\title{
A Rare Case of Ethambutol Induced Optic Neuritis in a Peripheral Health Institute of Northern India
}

\author{
Vatsayan Rahul $^{1}$, Sharma Deeksha ${ }^{2}$ \\ ${ }^{1}$ Incharge, Medicine Unit, Civil Hospital, Bhawarna, Distt Kangra (HP) \\ ${ }^{2}$ Ophthalmologist, Mobile Eye Unit, Zonal Hospital, Dharamshala, Distt Kangra (HP) \\ Corresponding Author: Sharma Deeksha
}

\begin{abstract}
Ethambutol (EMB) is one of the first-line drugs in the treatment of tuberculosis. EMB induces ocular toxicity which is a rare side-effect that is either dose-related or duration-related effect and is often reversible on therapy discontinuation. The toxicity has been reported at 4 to 12 months of the initiation of the therapy. We reported a rare case of EMB-induced optic neuritis after 1 month of initiation of the therapy. After the withdrawal of the drug, there was complete recovery of the patient. This case description would improve the understanding of the clinical presentation as well as the treatment of ethambutol optic neuritis, especially in recourselimited settings. It would also enrich the knowledge regarding the prevention strategies and timely recognition of the side effect.
\end{abstract}

Keywords: Ethambutol, Optic neuritis, Isoniazid

\section{INTRODUCTION}

Ethambutol (EMB) hydrochloride is one of the first-line drugs which is used to treat tuberculosis. Though infrequent, ocular toxicity in the form of optic neuritis (most commonly retro bulbar neuritis) is well recognized and a serious complication that has been documented since the drug was first used in the $1960 \mathrm{~s}^{1}$. EMB induced ocular toxicity which is often dependent on the dose and also on the duration of the therapy; however the toxicity is reversible when the therapy is discontinued ${ }^{2}$. Optic neuritis is the most important side-effect observed after the administration of Ethambutol. The optic neuritis is generally reversible and is specific to the dose and duration of treatment ${ }^{2}$.Prompt recognition of the side effect can help in preventing this sight-threatening side effect.

\section{CASE DESCRIPTION}

A 65-year female weighing $60 \mathrm{Kg}$ visiting our OPD in November 2019 and was diagnosed with Pulmonary tuberculosis, based on the sputum microscopy. After performing the necessary routine workup, she was started on the Anti-tubercular treatment consisting of the Isoniazid, Rifampicin, pyrazinamide, and Ethambutol (HRZE). The dose of ethambutol administered to the patient was $15 \mathrm{mg} / \mathrm{kg}^{3,4}$. Before the treatment eye examination was conducted which showed a corrected visual acuity of $6 / 6$ in both eyes. However, after one month the patient reported blurring of vision. Ophthalmologic examination revealed best corrected visual acuity of $6 / 12$ in the right eye and 6/18 in the left. After 2 months, an ophthalmologic examination revealed that best corrected visual acuity was $6 / 60$ in both eyes. Confrontation tests revealed bilateral central scotomas. Colour vision was tested using Ishihara charting, which was impaired in both eyes. On distant direct ophthalmoscopy, the optic disc of both the eyes was normal. Considering the possibility of EMB induced optic neuritis. EMB therapy was promptly stopped; however, the patient was continued on isoniazid, rifampicin, and pyrazinamide. There was a progressive but slow 
improvement in her vision. Within 3 months, the best corrected visual acuity was $6 / 12$ in the right eye and $6 / 9$ in the left eye. The patient is on regular follow-up and is improving.

\section{DISCUSSION}

Ethambutol (EMB) is the most common drug used in the treatment of tuberculosis. The drug is regarded as the least toxic of the first-line anti-tuberculosis drugs, it also has a very low incidence of ocular toxicity. 5,6 The ocular toxicity induced from ethambutol is not common at standard doses used in the anti-tubercular regimen. Optic neuritis is the most important and potentially the most serious side effect of EMB. Retro bulbar neuritis is the most common form, there is involvement of either the axial fibres or less commonly paraxial fibers. ${ }^{6,7}$ Clinically, and EMB optic neuropathy presents with the bilateral involvement of both the eyes as was seen in our case. However, the onset may be unilateral, but gradually, both eyes are involved. Symptoms of ethambutol toxicity have been reported between four and twelve months after starting EMB and are dose dependent, but rarely have been reported within few days of the start of therapy. ${ }^{8}$ Our patient was receiving standard $15 \mathrm{mg} / \mathrm{kg}$ of the dose, despite that the symptoms appeared within one month of the treatment. On examination central scotoma is common with the loss of colour vision. ${ }^{9}$ Various risk factors have been identified which can predispose to the ocular toxicity of $\mathrm{EMB}$, these include increasing age, prolonged duration of EMB, a higher dose, poor renal function, hypertension, diabetes, and concurrent optic neuritis, related to alcohol and tobacco use. ${ }^{10,11,12}$ The only treatment which has proven beneficial in EMB induced optic neuropathy is the discontinuation of the drug. Most patients will recover within weeks to months after stopping the drug, ${ }^{13}$. However, there are reports that vision may continue to decline or fail to recover even after the drug is stopped. ${ }^{14}$ The other drug, isoniazid which is frequently administered with EMB can also cause ocular toxicity and this often leads to confusion regarding the aetiology of ocular toxicity in patients receiving EMB. ${ }^{15}$ If visual impairment persists even after stopping of EMB, the stoppage of INH can be considered. Routine visual acuity testing is recommended before initiation of the EMB by various international socities. ${ }^{16}$ ${ }^{17}$ Pre-treatment renal function should be measured, any history of eye diseases, pretreatment record of visual acuity, routine visual acuity tests, and colour vision tests should be done in the patients on regular basis to avoid complications related to EMB toxicity. Physicians should frequently ask patients about changes in vision and make sure all patients understand that EMB should be immediately stopped and take medical advice immediately.

\section{CONCLUSION}

EMB, though being a safe antitubercular drug has the potential to cause serious ocular side effects in susceptible patients. Though the side-effect is known to be either dose or duration-related, sometimes it may occur even at lower doses and at shorter duration of treatments in susceptible individuals, leading to permanent vision loss. Even though, International guidelines on prevention and early detection of EMB induced ocular toxicity have been published, the physicians in recourse limited settings should be aware of the side effects and the management of this potential sight-threatening side effect. There is also a need to educate the patients about side-effects and check regular vision tests for early toxicity detection. If there is no vision improvement even after withdrawal of EMB, isoniazid toxicity should also be considered and the drug should also be stopped.

Acknowledgement: None

Conflict of Interest: None

Source of Funding: None 


\section{REFERENCES}

1. Carr RE, Henkind P. Ocular manifestations of ethambutol, Toxic amblyopia after administration of an experimental antituberculous drug. Arch Ophthalmol. 1962; 67(5):566-71.

2. Chatterjee VKK, Buchanan DR, Friedmann AI, Green M. Ocular toxicity following ethambutol in a standard dosage. Br J Dis Chest. 1986; 80:288-91.

3. Yoon YH, Jung KH, Sadun AA, Shin HC, Koh JY. Ethambutol-induced vacuolar changes and neuronal loss in rat retinal cell culture: mediation by endogenous zinc. ToxicolApplPharmacol. 2000; 162(2):10714.

4. Sivakumaran P, Harrison AC, Marschner J, Martin P. Ocular toxicity from ethambutol: a review of four cases and recommended precautions. N Z Med J. 1998; 111(1077): 428-30.

5. Yee D, Valiquette C, Pelletier M, Parisien I, Rocher I, Menzies D. Incidence of serious side effects from first-line antituberculosis drugs among patients treated for active tuberculosis. Am J RespirCrit Care Med. 2003; 167:1472-7.

6. Citron KM, Thomas GO. Ocular toxicity from ethambutol. Thorax. 1986; 41:737-9.

7. Chen L, Liang Y. Optic nerve neuropathy by ethambutol toxicity. ZhonghuaJie He He Hu Xi ZaZhi. 1999; 22:302-4.

8. Schild HS, Fox BC. Rapid-onset reversible ocular toxicity from ethambutol therapy. Am J Med. 1991; 90:404-6.

9. Melamud A, Kosmorsky GS, Lee MS. Ocular ethambutol toxicity. Mayo Clin Proc. 2003; 78:1409-11.

10. Chen HY, Lai SW, Muo $\mathrm{CH}$, Chen PC, Wang IJ. Ethambutol-induced optic neuropathy: A nationwide population-based study from Taiwan. Br J Ophthalmol. 2012; 96:1368-71.

11. Murray FJ. US Public Health Service experience with ethambutol. International Congress of Chemotherapy. Vienna. 1967; 6:339.

12. Chuenkongkaew W, Samsen P, Thanasombatsakul N. Ethambutol and optic neuropathy. J Med Assoc Thai. 2003; 86: 622-5.

13. Ezer N, Benedetti A, Darvish-Zargar M, Menzies D. Incidence ofethambutol-related visual impairment during treatment of active tuberculosis. Int J Tuberc Lung Dis. 2013; 17:447-55.

14. Chai SJ, Foroozan R. Decreased retinal nerve fiber layer thickness detected by optical coherence tomography in patients with ethambutol-induced optic neuropathy. Br J Ophthalmol. 2007; 91:895-7.

15. Garg P, Garg R, Prasad R, Misra AK. A prospective study of ocular toxicity in patients receiving ethambutol as a part of directly observed treatment strategy therapy. Lung India. 2015; 32:16-9.

16. Kaimbo WK, Bifuko ZA, Longo MB, Dralands L, Missotten L. Color vision in 42 Congolese patients with tuberculosis receiving ethambutol treatment. Bull SocBelgeOphtalmol. 2002:57-61.

17. Chemotherapy and management of tuberculosis in the United Kingdom: Recommendations 1998. Joint Tuberculosis Committee of the British Thoracic Society. Thorax. 1998; 53(7):536-48.

How to cite this article: Rahul V, Deeksha S. A rare case of ethambutol induced optic neuritis in a Peripheral Health Institute of Northern India. International Journal of Science \& Healthcare Research. 2021; 6(2): 14-16. DOI: https:// doi.org/10.52403/ijshr.20210403 